\title{
Çocuk Cerrahisi Kliniğinde Ultrasonografinin Yeri ve Önemi
}

\author{
IMPORTANCE AND ROLE OF ULTRASONOGRAPHY IN PEDIATRIC SURGERY CLINIC
}

\author{
Serkan ARSLAN ${ }^{1}$, Mehmet Hanifi OKUR ${ }^{1}$, Hikmet ZEYTUN ${ }^{1}$, Erol BASUGUY ${ }^{1}$, \\ Mehmet Şerif ARSLAN ${ }^{1}$, Bahattin AYDOĞDU ${ }^{1}$, Cemil GOYA ${ }^{2}$
}

1Dicle Üniversitesi Tıp Fakültesi, Çocuk Cerrahisi ve Çocuk Ürolojisi Anabilim Dalı

2Dicle Üniversitesi Tıp Fakültesi, Radyoloji Anabilim Dalı

\section{Serkan ARSLAN}

Dicle Üniversitesi

Tıp Fakültesi

Çocuk Cerrahi AD

DIYARBAKIR

Tel: (533) 6330774

e-posta:drserkanarslan@hotmail.com

\section{ÖZ}

Amaç: Son bir yılda çocuk cerrahisi kliniğimizde Ultrasonografi (USG) rehberliğinde yapılan işlemlerin ve çocuk cerrahları tarafından USG'nin kullanım alanlarının değerlendirmesi yapıldı. Klinisyenler tarafından USG'nin kullanımının ne derece yaygın olması gerektiği, radyologlar ve klinisyenlerin USG kullanımındaki yerlerinin belirlenmesi amaçlandi.

Gereç ve Yöntem: Bu çalışmada Ocak 2013-2014 yılları arasında 63 hasta geriye dönük olarak değerlendirildi.

Üriner sistem patolojisi ve/veya santral damar yolu gibi girişimsel işleme gereksinim olan hastalar USG ile değerlendirildi. Üriner sistem ile ilgili patoloji olduğu düşünülen hastalara başvuruları sırasında poliklinikte, klinisyen tarafından USG ile hastaların böbrek, üreter, ve mesaneleri değerlendirildi. Daha sonra radyolog tarafından USG'leri tekrarlanarak ikinci kez değerlendirme yapıldı. Santral kateter gereksinimi olan hastaların karotis arter ve internal juguler ven USG ile görüntülendikten sonra 45 derece açı ile seldinger yöntemi ile kateterizasyon sağlandıktan sonra işlem sonlandırıldı. Üriner sistem patolojilerinde nefrostomi veya sistofiks gerekli olan hastalara USG eşliğinde kateter takıldı. Tüm bu işlemler Çocuk Cerrahisi Kliniğinde gerçekleştirildi.

Bulgular: 2013-2014 yılları arasında 30'u erkek, 33'ü kız olmak üzere toplam 63 hastanın bilgileri geriye dönük olarak değerlendirildi. Hastaların 42 'sine tanısal amaçlı USG yapılırken, 21 hastaya invaziv girişimler USG eşliğinde yapılmıştır.

Sonuç: Üriner USG'ler her zaman hem radyolog, hem de klinisyen tarafından ayrı ayrı yapılarak çift kontrollü olarak değerlendirilmelidir. Ayrıca Santral Venöz Kateterizasyon (SVK), kateter ihtiyacı takılması gibi invaziv girişimlerin USG eşliğinde yapılması non invaziv olup işlem süresini kısaltmakta, hem de komplikasyonları azaltmaktadır. İnvaziv girişimler öğrenme eğrisine bağlı olarak değişmekle beraber yeterli sayıda tanısal amaçlı yapılan USG'lerden sonra yapılmalıdır.

Anahtar sözcükler: Ultrasonografi, çocuk, kateter, üroloji, kılavuz

ABTSTRACT

Objective: The operations made in the USG guidance by pediatric surgeons during the last year (2014) and the application areas of USG in our pediatric surgery department in one year period have been assessed. We aimed to determine what extent the USG should 
be used by clinicians, and the positions of radiologists and clinicians in the usage of USG. Material and Method: In this study 63 patients were evaluated retrospectively between January 2013-2014. Patients who needed urinary system pathology and/or central vascular access have been evaluated with USG. Patients who were thought to have a pathology urinary system have been evaluated in kidney, ureter and bladder with USG by a clinician. Then, the USG was repeated and second evaluation was done by a radiologist. Patients who needed central catheter were monitorized with carotid artery and internal jugular ven USG and then the operation was finalized after catheterization was provided with the seldinger method with a $45^{\circ}$ angle. Urinary tract pathology in patients who need nephrostomy catheter or sistofiks was inserted guided USG. All these applications was performed in pediatric surgery clinic.

Results: Between 2013-2014 information about 63 patients (30 male, 33 female) were evaluated retrospectively. Diagnostic USG was done to 42 of them, invasive attempts were done to 21 of them with USG.

Conclusions: Urinary USG always shall be evaluated double controlled by a radiologist and clinician. Also, invasive attempts like venous catheterization, catheter fastening are non invasive operations and shortens the operation period and decreases the complications. Invasive operations change according to the learning curve and they shall be done after sufficient diagnostic USGs.

Keywords: Ultrasonography, pediatri, catheter, urology, guide

Ultrasonografi (USG) kolay uygulanabilmesi, non-invaziv olması, düşük maliyet gerektirmesi ve hemen her yerde bulunabilmesi nedeniyle klinisyenlerin aktif olarak kullandığı bir görüntüleme cihazıdır. Ancak kullanıcı bağımlı olması dezavantajıdır $(1,2)$. Son yıllarda USG tanısal olarak kullanılmasının dışında Santral Venöz Kateterizasyon (SVK), Kemoterapi (KT) port kateteri, perkütan nefrostomi, sistofiks takılması gibi çeşitli invaziv girişimler USG rehberliğinde uygulanmaktadır. Bu da teknik başarısızlıkları en aza indirgeyip daha az komplikasyonlara ve skopi kullanımını ve dolayısıyla radyasyona maruz kalmasını azaltmaktadir (3-5).

Son bir yılda çocuk cerrahisi kliniğimizde USG rehberliğinde yapılan işlemlerin ve çocuk cerrahları tarafından USG'nin kullanım alanlarının değerlendirmesi yapıldı. Klinisyenler tarafından USG'nin kullanımının ne derece yaygın olması gerektiği, radyologlar ve klinisyenlerin USG kullanımındaki yerlerinin belirlenmesi amaçlandı.

\section{GEREÇ VE YÖNTEM}

Bu çalışmada Ocak 2013-2014 yılları arasında 63 hasta retrospektif olarak değerlendirildi. Poliklinikte üriner sistem ile ilgili olan hastalara klinisyen tarafından USG yapıldı. Hastaların böbrek, üreter çapı ve mesane yapısı değerlendirildi. Daha sonra radyolog tarafından hastaların USG'leri tekrarlanarak ikinci kez değerlendirme yapıldı. Gerek duyulduğu durumlarda radyolog ile görüşülerek
USG tekrar edildi. Santral damar yolu için girişimsel işlem ihtiyacı olan hastalar internal juguler ven kateterizasyonu için $3 \mathrm{~cm}$ lineer $5 \mathrm{MHz}$ transducer prob sağ supraklaviküler bölgeye steril olarak yerleştirildi. Carotis arter ve internal juguler ven USG ile görüntülendikten sonra 45 derece açı ile SVK iğnesi internal juguler vene girildi (Resim 1,2). Klavuz teli damar içerisinden kalbe kadar ilerletildi (Resim 3). Skopi ile yeri kontrol edildikten sonra dilatasyon yapıldi. Daha sonra KT port kateteri veya SVK takıldı.

Üriner sistem patolojisi düşünülen hastalara sistofiks kateteri ise suprapubik bölgeye konulan steril USG probu ile dolu mesane görüldükten sonra sistofiks mesane içerisine yerleştirildi.

Nefrostomi kateteri konulan hastalar ise yine aynı şekilde USG probu ile dilate pelvis görüntülendikten sonra kateter iğnesi pelvise ilerletildi. Daha sonra önce klavuz tel daha sonra ise kateterler böbrek pelvisi içerisine yerleştirildi. Tüm bu işlemler Çocuk Cerrahisi Kliniğinde gerçekleştirilmiştir.

\section{BULGULAR}

2013-2014 yılları arasında 30'u erkek, 33'ü kız olmak üzere toplam 63 hastanın bilgileri geriye dönük olarak değerlendirildi. Hastaların tanısal amaçlı üriner sistem değerlendirilmesi yapılan 41 hastanın 9'una girişimsel işlem uyguland. Santral kateter gereksinimi olan 13 hastaya da girişimsel işlem uygulandı. Toplamda 41 tanısal USG yapılır- 
ken, 22 hastaya invaziv girişimler esnasında USG rehberliğinde yapılmıştır. Bu hastaların hiç birinde erken dönemde veya işlem esnasında komplikasyon görülmez iken, bir hastada 7. günde kateterin tıkanmasına bağlı revizyon yapılmıştır. Yapılan işlemlerle ilgili detaylar Tablo'da gösterilmiştir.

\section{TARTIŞMA}

USG renal parankim kalınlığı, anterior-posterior çap, böbrek taşı, üreterde dilatasyon, böbreklerin boyutları, mesanenin kalınlığı, trabekülasyon varlığı gibi birçok paramatrenin değerlendirilmesinde önemlidir (2). Buna karşın cerrahi gereklilik için standardize edilmiş değerlendirmeler yetersizdir. Hidronefrozda alternatif sinıflandırmalar kullanılmakla birlikte en sık Fetal Üroloji Birliği (SFU)'nin tanımladığı sınıflama kullanılmaktadır $(6,7)$. Çalışmamızda öncelikle poliklinikte üriner USG'ler yapılmıştır. Klinisyen öncelikli olarak gerekli değerlendirmeleri yaptıktan sonra radyoloji tarafından tekrar değerlendirilerek mevcut rapora göre hem kendi yaptığı USG'yi kontrol etmiş olacak, hemde radyolog tarafından yapılan USG' de yanlışlık varsa kontrol edilmiş olacaktır. Böylece daha doğru tanı konulmuş, daha az hata yapılmış olacaktır.

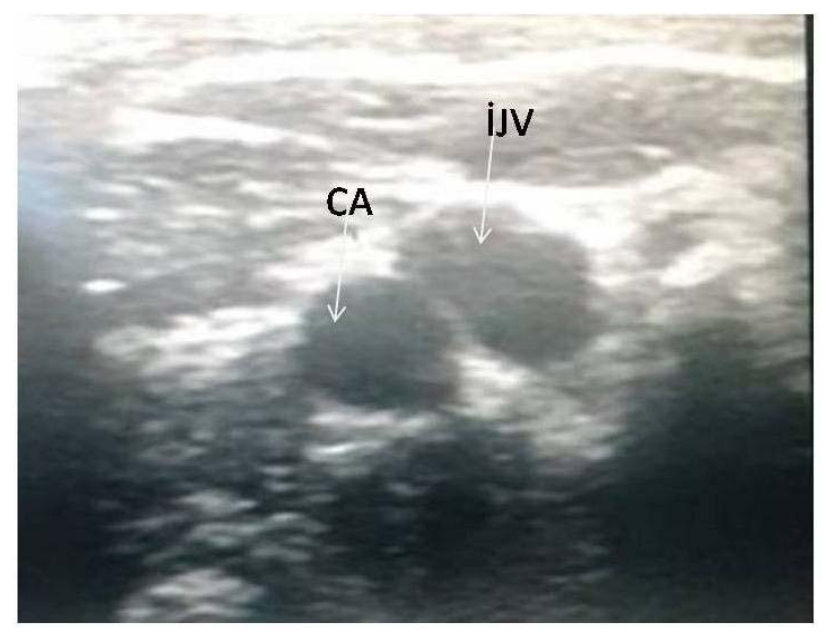

Resim 1. Ultrasonografi ile carotis arter ve internal juguler ven görünümü

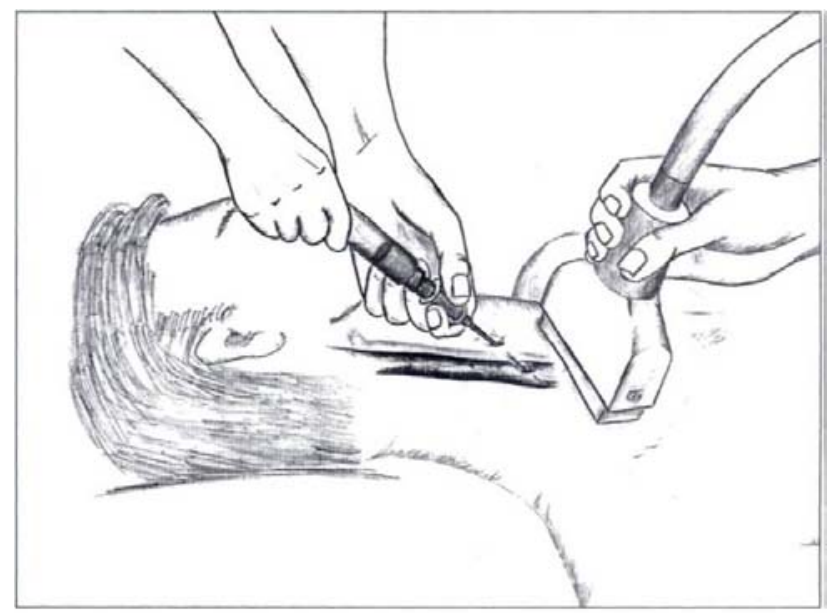

Resim 2. Ultrasonografi eşliğinde internal juguler vene girişim

Üriner sistemin değerlendirilmesinde USG önemini korumasına karşın halen birçok çocuk cerrahi kliniğinde radyologlar USG'yi yapmakta ve klinisyenler USG raporlarını değerlendirmektedir. Böylece acil durumlarda girişimsel işlemler için zorluk çekilmektedir.

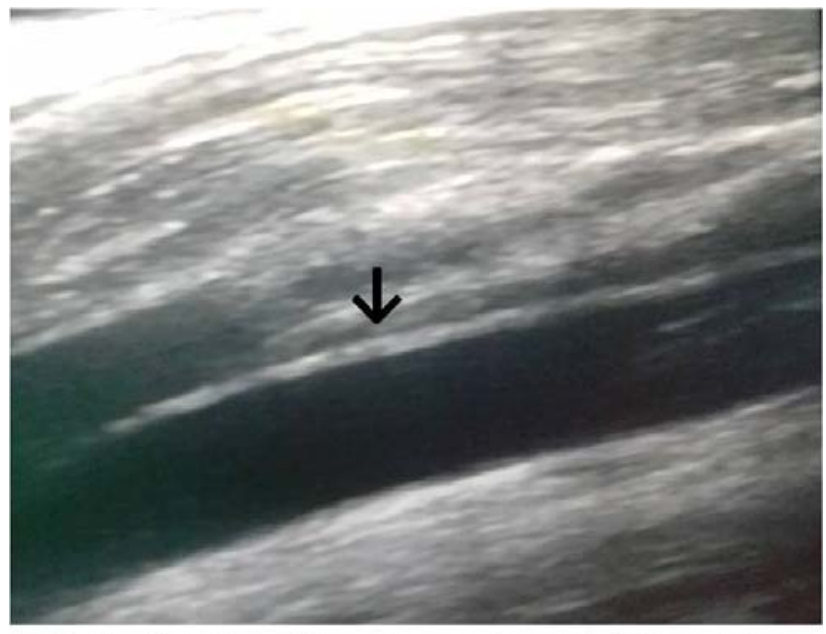

Resim 3. İnternal juguler ven içerisindeki kateter görünümü 
Tablo. USG eşliğinde yapılan işlemler

\begin{tabular}{lll}
\hline & Hasta sayısı & Komplikasyon \\
\hline Tanısal amaçlı üriner sistem değerlendirilmesi & 42 & - \\
USG eşliğinde girişimsel işlemler & 21 & - \\
Üriner sistem için girişimler & 9 & - \\
Nefrostomi kateteri takılması & 5 & - \\
Sistofiks kateteri takılması & 2 & - \\
USG eşliğinde perkutan girişim & 2 & - \\
Santral kateter için girişimler & 12 & - \\
Santral juguler kateter takılması & 7 & 1 hasta, 7.gün kateter revizyonu \\
Juguler kemoterapi port kateteri takılması & 5 & - \\
\hline Toplam & $\mathbf{6 3}$ & $\mathbf{1}$ \\
\hline
\end{tabular}

Mesaneye sistofiks kateteri yerleştirilmesi bazı kliniklerde körlemesine yapılmaktadır. Ancak geçirilmiş mesanenin ameliyatlarında, mesane travmalarında, mesanenin normal anatomik pozisyonda olmayabileceğinden işlem s1rasında barsak, damar veya diğer organ yaralanmaları olabilmektedir (8). Kliniğimizde 2 hastaya USG eşliğinde mesanenin dolu olduğundan emin olduktan sonra ve anatomik lokalizasyonu görülerek USG eşliğinde yapılmıştır. Bu nedenle diğer organ yaralanmalarının önlenmesi için USG eşliğinde işlemlerin yapılmasının daha güvenli olduğunu düşünüyoruz. Nefrostomi için ideal olan USG eşliğinde veya flouroskopi eşliğinde yapılmasıdır $(4,9)$. Sıklıkla radyologlar tarafından yapılmaktadır. Çalışmamızda USG eşliğinde bir hastaya nefrostomi, bir hastaya ise perkütan nefrolitotomi öncesi girişim yapılmıştır. Çalışmamızda cerrahi anatomiye daha hakim olan cerrahların (klinisyen) radyoloji sonrası/öncesi USG yapması çift kontrollu değerlendirmeye olanak sağlaması ve radyoloğun bulunmadığı acil durumlarda üriner kateter yerleştirme kolaylığı sağlaması nedeniyle önemli olduğunu düşünüyoruz.

McGee ve ark. çalışmasında USG eşliğinde yapılan SVK başarı oranının arttı̆̆ını belirlemişlerdir. Ayrıca kateter yerleştirmedeki başarısızlık ve komplikasyon oranını daha düşük bulmuşlardır $(4,10)$. Teichgräber ve ark. çalışmasında USG ve anatomik olarak işaretlenmiş olarak kateterize edilen iki grubu karşılaştırmış, bunlardan USG rehberliğinde SVK \%96 iken, anatomik olarak işaretlenen hastaların ilk girişinde başarı oranını \%52 saptamışlardır (11). Çalışmamızda USG eşliğinde 5 hastaya SVK, 4 hastayada
KT port kateteri takılmıştır. Hiçbir hastada intraoperatif ve erken dönemde port ve SVK komplikasyonu görülmez iken 7. gün kateterin çalışmamasına bağlı kateter revizyonu yapılmıştır. USG ile yapılan kateterizasyon daha kısa sürede yapılmış, erken dönemde herhangi bir komplikasyon olmamıştır.

\section{SONUÇ}

Üriner USG'ler her zaman hem radyolog, hem de klinisyen tarafından ayrı ayrı yapılarak çift kontrollü olarak değerlendirilmelidir. Ayrıca SVK, kateter takılması gibi invaziv girişimlerin USG eşliğinde yapılması non invaziv olup işlem süresini kısaltmakta, hem de komplikasyonları azaltmaktadır ancak invaziv girişimler öğrenme eğrisine bağlı olarak değişmekle beraber yeterli sayıda tanısal amaçlı yapılan USG'lerden sonra yapılmalıdır. Cerrahi anatomiye daha hakim olan cerrahların (klinisyen) radyoloji sonrası / öncesi USG yapması radyoloğun bulunmadığı acil durumlarda üriner veya santral kateter yerleştirme kolaylığı sağlaması nedeniyle önemli olduğunu düşünüyoruz.

\section{KAYNAKLAR}

1. Arslan S, Turan C, Doganay S, Güzel M, et al. The effectiveness of pneumoreduction for intussusception. Ann Ital Chir 2014;28:85.

2. Başaklar AC, Türkyılmaz Z. Genitoüriner Travma. In: Başaklar AC (ed), Bebek ve Çocukların Cerrahi ve Ürolojik Hastalıkları. Ankara: Palme Yayıncılık, 2006: 1787-1810. 
3. Brooks AJ, Alfredson M, Pettigrew B, et al. Ultrasoundguided insertion of subclavian venous access ports.Ann $\mathrm{R}$ Coll Surg Engl 2005;87:25-27.

4. Gualtieri E, Sipperley ME, Thompson DR. Subclavian venouscatheterization - greater success rate for less experienced operators using ultrasound guidance. Crit Care Med 1995; 23: 692.

5. Kitchens DM, Herndon CD. Postnatal imaging of antenatal hydronephrosis. Scientific WorldJournal 2009;9:393-399.

6. McGee DC, Gould MK. Preventing complications of central venous catheterization. N Engl J Med 2003; 348:11231133.

7. Onen A. An alternative grading system to refine the criteria for severity of hydronephrosis and optimal treatment guidelines in neonates with primary UPJ-type hydronephrosis. J Pediatr Urol 2007;3:200-205.

8. Pedersen JF. Percutaneous nephrostomy guided by ultrasound. J Urol 1974;112:157-159.

9. Saçak V, Mansuroğlu B, Toktaş G ve ark. Girişimsel ÜroRadyoloji Kavramı ve illtrasonografi Klavuzluğunda Yaptığımız Müdahaleler. Istanbul Tıp Dergisi 1995; 3:35-37.

10. Teichgräber UK, Benter T, Gebel M, Manns MPA. Sonographically guided technique for central venous access. AJR Am J Roentgenol 1997;169:731-733.

11. Tovey G, Stokes M. A survey of the use of 2D ultrasound guidance for insertion of central venous catheters by UK consultant paediatric anaesthetists. Eur J Anaesthesiol 2007;24:71-75. 